\title{
Online Education as a Solution to Managing and Sustaining Foreign Aid: Comparison Between the European Cases and Others
}

\author{
Jinhwan Oh \\ Correspondence: Jinhwan Oh, Graduate School of International Studies, Ewha Womans University, Seoul, South Korea. \\ E-mail: joh@ewha.ac.kr
}

Received: February 23, 2020

Accepted: March 30, 2020 Online Published: April 9, 2020

doi:10.5539/res.v12n2p12

URL: https://doi.org/10.5539/res.v12n2p12

\begin{abstract}
Inbound education official development assistance (ODA) has been known to be spread across regions regardless of geographic proximity. This not only negatively impacts effectiveness to manage aid, but also to sustain aid long-term. This study examines aid disbursement pattern of the United Kingdom, Germany, Australia, and South Korea, which are all members of OECD's Development Assistance Committee that allocates inbound education ODA. With the empirical results confirming Korea's lack of concentration in education ODA, this study recommends establishing satellite campuses as a more viable, operative solution than the previously suggested solution of establishing a specialized agency focusing on scholarship programs. As validated by Nagoya University's Asian Satellite Campuses Institute (ASCI), transferring much of work to the online platform reduces time and financial costs. Furthermore, satellite campuses are expected to facilitate various means of partnerships among aid donor countries that are implementing similar programs. International collaborative efforts could help improve the quality of inbound education and play an important role in attracting bright prospective students. Thus, donor countries could utilize online education platform to overcome severe geographic obstacles in distance education and increase effectiveness of its inbound education ODA.
\end{abstract}

Keywords: inbound education aid; aid effectiveness; satellite campus

\section{Introduction}

South Korea's inbound long-term scholarship program was pointed out as an example of "thinly spread" Official Development Assistance (ODA) in an OECD peer review (2012). According to Oh (2017), South Korea's ODA is dispersed without considering geographic proximity, and this affects the program's effectiveness in managing and sustaining aid, which contradicts Japan's ODA allocation pattern - highly concentrated to a limited number of Asian countries. This study reexamines the same issue of concern by conducting a more in-depth analysis and shifts focus to other member countries of the Development Assistance Committee (DAC) that provide education ODA, namely, the United Kingdom, Germany, and Australia. To state the conclusion up front, there is a significant negative correlation between the geographical distance and the number of scholars receiving donor countries' inbound education ODA, thus confirming the weaker degree of concentration of Korea's education ODA.

Furthermore, this study does not merely diagnose the present state of affairs but extends its approach to prescribe realistic solutions. To address the diluted nature of Korea's inbound education ODA, Oh (2017) advised establishing a separate agency solely for managing scholarship programs, but this is not as easy as it seems and is still unfeasible for many countries. Taking into consideration the budgetary constraints and existing circumstances, establishing an online education platform should be given due consideration; this is a practical, workable solution that could compensate for the weak points of inbound education ODA allocation pattern.

The remainder of this paper is organized as follows. Next section delineates research methods and data used. The following section discusses empirical findings of this study. The last Section 4 specifies the details regarding online education platform. Section 5 concludes.

\section{Methods and Data}

This study hypothesized a significant negative correlation between geographical distance and number of scholarship recipients for the three donor countries (United Kingdom, Germany, and Australia), and this hypothesis was tested to determine the degree of statistical significance of the concentrations of the countries' inbound education ODA. The gravity model was used to analyze the flow of scholarship recipients.

First, the proxy for mass was population given that it is a more relevant pull factor that is likely to have a positive impact 
on the number of scholarship recipients. Thus, this coefficient was expected to have a positive sign. Based on previous research (McCallum, 1995; Wei, 1996), we attempted to use GDP as an instrumental variable for population to avoid any possible endogeneity and reverse causality issues; GDP is known to be closely related with population yet not with error term. Second, distance is a key parameter in explaining the gravity model. Because of the negative impact of distance on the amount of flow between two masses, it was hypothesized that the number of scholar recipients would decrease with increasing distance and vice versa. Accordingly, the expected sign of the corresponding coefficient was negative. Last, an ODA dummy variable was added to investigate whether there was a positive correlation between scholarship allocation and the host country's amount of ODA in general. Because education aid is often endowed by means of ODA, the coefficient for ODA dummy was expected to be positive. The basic model is as follows:

$$
y_{i j t}=a+\text { bpopulation }_{i j t}+\text { cdistance }_{i j}+\mathrm{d} X_{i j t}+u_{i j t}
$$

where $y_{i j t}$ is the percentage of scholars receiving education ODA $(i)$ to study in host countries United Kingdom, Germany, and Australia ( $j$ ), respectively, out of the total number of scholars in a given year $(t)$. Percentage is utilized as a unit for the dependent variable to make the comparison among the varying number of inbound education scholarship recipients of each aid donor countries more consistent. With population being a proxy for mass, population ${ }_{i j t}$ represents the population of an aid recipient country in a given year. Distance is the only time-invariant variable in the equation; distance $_{i j}$ measures the distance between host and recipient countries. The variables of population and distance are $\log$ transformed. $X_{i j t}$ denotes other controlling factors that could affect the number of scholars receiving inbound education ODA. $u_{i j t}$ represents the error term.

For the United Kingdom, data regarding the number of scholarship recipients were acquired from the Commonwealth Scholarship Commission annual report; the UK's inbound education scholarship recipients were from 53 countries, and the time frame for analysis was 15 years from 2000 to 2015 . To create a balanced panel data set, missing values were treated with average values of three time frames: 2000-2005, 2006-2010, and 2011-2015. For Germany, data were obtained from the annual reports of the German Academic Exchange Service. ${ }^{1}$ Scholarship recipients were from 181 countries, and six years of data were available, from 2012 to 2017. For Australia, data on the scholarship recipients were from international student enrollment data published by the Australian government; a full data set from 2002 to 2009 was available on scholarship recipients from 181 countries. The data sources for the independent variables were as follows: population was obtained from Worldometers, a real-time, worldwide statistical database; GDP (constant 2010 US\$) was acquired from the World Bank's World Development Indicator. ODA data was collected from OECD's Query Wizard for International Development Statistics, and distance data was obtained from and distancecalculator.net.

Panel random effects was employed in this study. Fixed effects provide good estimates because these models control for the effects of time-invariant variables, but that becomes a stumbling bloc because they fail to measure essential time-invariant variables, that is, distance, in the current study. Such limitation has been addressed earlier by Baldwin and Taglioni (2006). On the contrary, a random-effects model presumes that the error term of the entity is not correlated with the estimated coefficients, which consequently allows time-invariant variables to function as explanatory ones.

\section{Empirical Findings}

In this section, we empirically tested whether other country donors' inbound education ODA was consistent with the gravity model. As the gravity model predicts, we expected to observe a clear negative correlation between distance and the number of scholarship recipients. In brief, the finding was that distance was negative for all three countries. For the other independent variables, population, GDP, and ODA dummy, the coefficients were expected to be positive because these factors are estimated to be directly proportional to the number of scholarship recipients. Among all variables, population consistently revealed the highest degree of significance for all the aid donor countries.

First, the regression results for the United Kingdom shown in Table 1 indicate a high level of significance overall. The population variable in particular maintains $1 \%$ significance throughout Equations 1 to 5; holding other variables constant, a $1 \%$ increase in population resulted in an approximately $0.5 \%$ increase in the number of scholarship recipients. This outcome validates the hypothesis that predicts a positive relationship between population and the number of scholarship recipients. Distance is negative throughout all the models: A $1 \%$ increase in distance explained a $0.5 \%-0.6 \%$ decrease in the scholarship recipients. The significance in this relationship was weaker than for population (10\% in Column 3 and not significant in the next one); one possible explanation for these observations is former British colonies. In this study, the list of United Kingdom's inbound education scholarship recipient countries comprised independent states recognized as member states of the United Nations ${ }^{2}$ and thus excluded British dependent territories. Nonetheless, unsurprisingly given Britain's historical past as an "empire on which the sun never sets," a significant number of countries that received British

\footnotetext{
1 Deutscher Akademischer Austausch Dienst in German.

2 As of December 2018, the United Nations has 193 Member States (United Nations, n.d.).
} 
education scholarship were countries with colonial ties. In fact, among 52 countries that were receiving British education scholarship, 22 of them ${ }^{3}$ situated in regions around the world were former British colonies. Lastly, the coefficient for the ODA dummy was positive. It can be inferred from the coefficients that the number of scholarship recipients, holding other variables constant, is nearly two or three times larger for countries that receive ODA from Britain $[\exp (0.603)=1.828$ and $\exp (1.155)=3.174]$.

Second, Germany's empirical results presented even higher significance than that for the United Kingdom for all of the variables including the ODA dummy variable. We observed a significant positive relationship between the number of scholarship recipients and population. Holding all other variables constant, the estimated coefficient shows that a $1 \%$ increase in population results in an increase in the number of scholarship recipients by approximately $0.7 \%$, which is $0.20 \%$ higher than the rate for the United Kingdom. Similarly, the distance coefficients were consistently negative throughout all the equations, validating the greater concentration of Germany's inbound education scholarship programs, which prioritize neighboring countries. The ODA dummy variable maintained a strong positive relationship with number of scholarship recipients, implying that Germany grants more education scholarship to students of developing countries in the form of ODA, although the magnitude is less than that of the United Kingdom. Other things equal, education scholarship allocation is 1.5 times larger for countries that receive Germany's ODA [ $\exp (0.364)=1.439$ and $\exp (0.436)=1.546]$. This is to a smaller degree than that in the United Kingdom.

Last, Australia also has statistically significant regression results. While positive correlation between the number of scholarship recipients and population and the negative correlation between the number of scholarship recipients and distance closely resemble the empirical results for the other countries, one key difference is the shift of the ODA dummy variable from a positive to a negative sign. This dummy variable maintained a clear negative value throughout all equations, implying that Australia does not necessarily grant its education scholarship to countries of the developing world or the countries where it allocates its ODA. Holding other variables constant, countries that received Australian ODA had $10 \%$ to $15 \%$ fewer scholarship recipients than countries that did not receive ODA $[\exp (-1.899)=0.150$ and $\exp (-2.259)=0.104]$. A random effect panel regression was used to perform a robustness check, and the results indicated that the dummy coefficient still coincided with others.

Table 2 adds squared term for population and distance to provide sensitivity testing results that confirmed the robustness of the results shown in Table 1. Population does not have a uniformly consistent pattern; it is linearly positive and quadratically negative for the United Kingdom and opposite for Australia; separately, while the positive effect of population from Table 1 diminishes for more populous countries in the United Kingdom, the same effect becomes more distinctive in Australia; for Germany, neither the linear nor the quadratic term was significant; there were no meaningful results. For distance, all of the countries consistently showed a positive linear term and negative square term. This clarifies the decreasing pattern of distance derived from Table 1. ODA donor countries fewer scholarship recipients from more distant countries, but the absolute effect increases exponentially, as shown in Table 2. The number of scholarship recipients decrease in great numbers as distance increases.

\footnotetext{
3 Pacific: Fiji (1)

Caribbean: Antigua and Barbuda, Bahamas, Barbados, Belize, Dominica, Grenada, Jamaica, St. Lucia, St.Vincent and the Grenadines, Trinidad and Tobago (10)

Southeast Asia: Malaysia, Singapore (2)

Sub-Saharan Africa: Kenya, Mauritius, Nigeria, Seychelles, Sierra Leone, the Gambia (6)

Europe: Cyprus, Malta (2)

Australasia: Australia (1)
} 
Table 1. Regression results for United Kingdom, Germany, and Australia

\begin{tabular}{|c|c|c|c|c|c|c|c|c|c|c|c|c|c|c|c|}
\hline \multirow{4}{*}{$\begin{array}{l}\text { Independent } \\
\text { variable } \\
\text { Log } \\
\text { population }\end{array}$} & \multicolumn{5}{|c|}{ United Kingdom } & \multicolumn{5}{|c|}{ Germany } & \multicolumn{5}{|c|}{ Australia } \\
\hline & 1 & 2 & 3 & 4 & 5 & 1 & 2 & 3 & 4 & 5 & 1 & 2 & 3 & 4 & 5 \\
\hline & $0.511^{* * *}$ & $0.516^{* * *}$ & $0.522^{* * *}$ & $0.554^{* * *}$ & $0.509^{* * * *}$ & $0.716^{* * *}$ & $0.713^{* * *}$ & $0.684^{* * * *}$ & $0.739 * * *$ & $0.735^{* * *}$ & $0.711^{* * *}$ & $0.758^{* * *}$ & $0.904^{* * *}$ & $0.867^{* * *}$ & $1.227^{* * *}$ \\
\hline & -0.03 & -0.03 & -0.039 & -0.047 & -0.041 & -0.022 & -0.022 & -0.067 & -0.046 & -0.035 & -0.025 & -0.026 & -0.079 & -0.069 & -0.047 \\
\hline \multirow[t]{2}{*}{ Log distance } & $-0.584 * *$ & $-0.533^{* *}$ & $-0.534^{*}$ & -0.536 & $0.605 * * *$ & $0.202^{* * *}$ & $0.298^{* * *}$ & $0.353^{* * *}$ & $0.352^{* * *}$ & $0.177^{* * *}$ & $-1.953^{* * *}$ & $-2.766^{* * *}$ & $-3.082^{* * *}$ & $-3.020 * * *$ & $-2.700 * * *$ \\
\hline & -0.24 & -0.241 & -0.3 & -0.394 & -0.199 & -0.043 & -0.045 & -0.103 & -0.102 & -0.043 & -0.155 & -0.162 & -0.423 & -0.418 & -0.178 \\
\hline \multirow[t]{2}{*}{ ODA dummy } & & $0.603^{* *}$ & $0.632^{*}$ & $1.155^{* * *}$ & & & $0.364^{* * *}$ & $0.412^{* *}$ & $0.436^{* *}$ & & & $-1.899 * * *$ & $-2.258 * * *$ & $-2.259 * * *$ & \\
\hline & & -0.287 & -0.351 & -0.353 & & & -0.088 & -0.204 & -0.202 & & & -0.105 & -0.265 & -0.262 & \\
\hline \multirow[t]{2}{*}{ Constant } & -0.422 & -1.492 & -1.583 & -2.283 & -0.208 & $6.508^{* * *}$ & $5.912^{* * *}$ & $5.113^{* * *}$ & $5.989^{* * *}$ & $7.017^{* * *}$ & $11.432^{* * *}$ & $19.535^{* * *}$ & $20.153^{* * *}$ & $20.189^{* * *}$ & $10.211^{* * *}$ \\
\hline & -2.306 & -2.304 & -2.904 & -3.846 & -1.95 & -0.47 & -0.463 & -1.306 & -1.077 & -0.619 & -1.42 & -1.496 & -3.982 & -3.945 & -1.574 \\
\hline $\begin{array}{l}\text { Estimation } \\
\text { method: }\end{array}$ & OLS & OLS & $\mathrm{RE}$ & $\mathrm{RE}$ & IV & OLS & OLS & $\mathrm{RE}$ & $\mathrm{RE}$ & IV & OLS & OLS & $\mathrm{RE}$ & $\mathrm{RE}$ & IV \\
\hline Observations: & 145 & 145 & 145 & 96 & 144 & 956 & 956 & 956 & 800 & 898 & 993 & 993 & 993 & 923 & 966 \\
\hline Adjusted $\mathrm{R}^{2}$ : & 0.637 & 0.6515 & 0.6515 & 0.6817 & 0.6339 & 0.4643 & 0.4716 & 0.4706 & 0.4762 & 0.4793 & 0.3761 & 0.5071 & 0.5062 & 0.508 & 0.2111 \\
\hline
\end{tabular}

Notes: Standard errors in parentheses and *,**,*** indicate significance at the $10 \%, 5 \%$, and $1 \%$ level respectively.

Equation (1): Basic equation, population and distance only.

Equation (2): Full equation, including population, distance, and ODA dummy.

Equation (3): Full equation, including population, distance, and ODA dummy.

Equation (4): Full equation, includes lagged population variable.

Equation (5): Logarithms of GDP used as instruments for population.

Table 2. Sensitivity test results

\begin{tabular}{lrrr}
\hline Independent variable & United Kingdom & \multicolumn{1}{c}{ Germany } & \multicolumn{1}{c}{ Australia } \\
\hline Log population & $1.014^{* *}$ & 0.223 & $-1.527^{* * *}$ \\
& $(0.406)$ & $(0.624)$ & $(0.573)$ \\
Log distance & $19.367^{* * *}$ & $3.444^{*}$ & $32.764^{* * *}$ \\
& $(5.376)$ & $(1.962)$ & $(12.289)$ \\
ODA dummy & $0.878^{* *}$ & 0.336 & $-2.400^{* * *}$ \\
& $(0.432)$ & $(0.213)$ & $(0.264)$ \\
Log population ${ }^{2}$ & -0.016 & 0.016 & $0.077^{* * *}$ \\
& $(0.013)$ & $(0.020)$ & $(0.019)$ \\
Log distance & & $-0.239 *$ & $-1.962 * * *$ \\
& $-1.118^{* * *}$ & $(0.122)$ & $(0.686)$ \\
Constant & $(0.308)$ & $-16.648 *$ & $-124.057 * *$ \\
& $-93.596^{* * *}$ & $(9.707)$ & $(55.117)$ \\
Estimation method: & $(23.920)$ & $\mathrm{RE}$ & $\mathrm{RE}$ \\
Observations: & $\mathrm{RE}$ & 800 & 923 \\
Adjusted $\mathrm{R}^{2}:$ & 96 & 0.4894 & 0.5597 \\
\hline
\end{tabular}

Notes: Standard errors in parentheses and $*, * *, * * *$ indicate significance at $10 \%, 5 \%$, and $1 \%$, respectively. Full equation with lagged population, lagged population squared, distance, distance squared, and ODA dummy.

\section{Establishing Online Education Platform}

The effect of distance is weaker in Korea with regard to major scholarship recipient countries. Table 3 illustrates Korea's aid allocation pattern, which is significantly negative for all countries with at least one scholarship recipient (consists of first four equations indicated as "all but zero"); however, the level of significance decreases when excluding countries with trifling portions (equations 5 to 7, denoted as "upper 75\%"). Moreover, the coefficients become insignificant when we only include countries whose portions are greater than the median (equations 8 to 10, indicated as "upper 50\%"). As Table 3 reveals, Korea's scholarship allocation pattern is less concentrated and thinly spread (OECD, 2012). 
Table 3. Regression results for Korea

\begin{tabular}{|c|c|c|c|c|c|c|c|c|c|c|}
\hline & \multicolumn{4}{|c|}{ All but zero } & \multicolumn{3}{|c|}{ Upper $75 \%$} & \multicolumn{3}{|c|}{ Upper $50 \%$} \\
\hline & 1 & 2 & 3 & 4 & 5 & 6 & 7 & 8 & 9 & 10 \\
\hline Log distance & $-0.609 * * *$ & $-0.412^{* * *}$ & $-0.559 * * *$ & $-0.607^{* *}$ & $-0.286^{*}$ & -0.144 & $-0.380^{* *}$ & 0.190 & 0.293 & 0.102 \\
\hline & $(0.139)$ & $(0.146)$ & $(0.145)$ & $(0.251)$ & $(0.165)$ & $(0.170)$ & $(0.173)$ & $(0.234)$ & $(0.206)$ & $(0.229)$ \\
\hline $\begin{array}{l}\text { Lag log } \\
\text { population }\end{array}$ & $0.129 * *$ & $0.154 * * *$ & $0.143^{* *}$ & 0.132 & 0.044 & $0.103^{*}$ & 0.091 & -0.040 & -0.023 & -0.017 \\
\hline & $(0.055)$ & $(0.057)$ & $(0.057)$ & $(0.098)$ & $(0.056)$ & $(0.062)$ & $(0.063)$ & $(0.073)$ & $(0.073)$ & $(0.072)$ \\
\hline Lag log trade & $\begin{array}{r}-0.242^{* * *} \\
(0.055)\end{array}$ & & $\begin{array}{r}-0.140^{* * *} \\
(0.051)\end{array}$ & $\begin{array}{r}-0.164^{* *} \\
(0.078)\end{array}$ & $\begin{array}{r}-0.267^{* * *} \\
(0.063)\end{array}$ & & $\begin{array}{r}-0.200^{* * *} \\
(0.063)\end{array}$ & $\begin{array}{r}-0.201^{* * *} \\
(0.072)\end{array}$ & & $\begin{array}{r}-0.128^{*} \\
(0.073)\end{array}$ \\
\hline Lag $\log$ ODA & $\begin{array}{r}0.326^{* * *} \\
(0.050)\end{array}$ & & & & $\begin{array}{r}0.311^{* * *} \\
(0.066)\end{array}$ & & & $\begin{array}{r}0.255^{* * *} \\
(0.096)\end{array}$ & & \\
\hline Priority country & & $\begin{array}{r}1.126^{* * *} \\
(0.175)\end{array}$ & $\begin{array}{r}1.056 * * * \\
(0.171)\end{array}$ & $\begin{array}{r}1.064 * * * \\
(0.295)\end{array}$ & & $\begin{array}{r}0.793^{* * * *} \\
(0.208)\end{array}$ & $\begin{array}{r}0.648^{* * *} \\
(0.209)\end{array}$ & & $\begin{array}{r}0.705^{* * *} \\
(0.256)\end{array}$ & $\begin{array}{r}0.582^{* *} \\
(0.268)\end{array}$ \\
\hline Constant & $\begin{array}{r}5.507^{* * *} \\
(1.543)\end{array}$ & $\begin{array}{r}2.541 \\
(1.635)\end{array}$ & $\begin{array}{r}4.453 * * * \\
(1.697)\end{array}$ & $\begin{array}{r}4.999 \\
(3.138)\end{array}$ & $\begin{array}{r}4.582^{* * *} \\
(1.740)\end{array}$ & $\begin{array}{r}1.671 \\
(1.837)\end{array}$ & $\begin{array}{l}4.598^{* *} \\
(1.949)\end{array}$ & $\begin{array}{r}2.377 \\
(2.232)\end{array}$ & $\begin{array}{r}0.713 \\
(2.044)\end{array}$ & $\begin{array}{r}2.699 \\
(2.354)\end{array}$ \\
\hline $\begin{array}{l}\text { Estimation } \\
\text { method: }\end{array}$ & OLS & OLS & OLS & $\mathrm{RE}$ & OLS & OLS & OLS & OLS & OLS & OLS \\
\hline Observation: & 330 & 337 & 335 & 335 & 236 & 237 & 236 & 158 & 159 & 158 \\
\hline
\end{tabular}

Source: Oh (2017). Notes: Standard errors in parentheses and *,**,*** indicate significance at $10 \%, 5 \%$, and $1 \%$ respectively. Standard errors are in parentheses. White standard heteroscedasticity robust standard errors. The dependent variable is the portion/percentage of scholarship recipients per country. Except for "priority country," a dummy variable that was 1 for Korea's priority partner countries and 0 otherwise, all independent variables are log transformed. Among them, population, trade, and official development assistance (ODA) are lagged by one year to avoid any potential endogeneity issues. The sample includes only countries with positive portions (all but zero), portions with $75 \%$ quantile (upper 75\%), and median (upper 50\%). This is the result from 2000 in which only two countries are selected. This analysis includes outliers, but even without them the results are almost the same. Countries with zero scholarship recipients are not included.

Recently, Korea International Cooperation Agency (KOICA) increased the number of countries to which it offers scholarships, from 31 in 2007 to 57 in 2014, encompassing a vast range of regions including Africa, the Americas, the Middle East, Oceania, Eastern Europe, and Central Asia. This pattern is quite contrary to the scholarship allocation patterns of Japan, where the 244 students who received long-term scholarships in 2017 were chosen from only 11 Asian countries (Oh, 2017). This geographic proximity allows host universities to send their faculty for external events such as promotional fairs, one-on-one interviews, alumni meets, and even briefing sessions for prospective students, as well as inviting alumnae to their alma maters, which helps facilitate sustainable relationships in the long-term.

While restructuring the allocation plan and concentrating more on nearby countries is the most desirable option, establishing an online education platform can be considered the most effective method under the current situation to supplement the weak concentration of Korea's education aid and increase its effectiveness. Widening access to tertiary education is one of the top global priorities as it relates to other issues concerning employment, and this goal is achievable in reality "only if we truly open up education and provide high-quality and easily accessible open educational resources (OER) and massive open online courses (MOOC) for all worldwide" (Ossiannilsson, Z. Altinay, \& F. Altinay, 2016, p.160). With socioeconomic changes followed by the computer communications revolution in the mid- $20^{\text {th }}$ century, the realm of education has undergone dramatic transformation, opening doors to new learning models and educational opportunities (Harasim, 2000; Carey, 2016). Bartholet et al. (2013) assert technology as the solution to bring "top-notch courses to the world's poorest citizens," and major MOOC platforms such as Udacity, Coursera, and edX have in fact proposed their ambition to deconstruct class and geographical barriers to higher education (51).

This type of benefit will be greater in the developing world, where students are less likely to receive education that meets the international standards, and geographic obstacles are is severe. Online platforms are effective means of delivering education in terms of both cost and method. In practice, a small nonprofit organization called Generation Rwanda has experimented with using MOOCs to educate Rwandan youth who were born during the time of Rwandan genocide in 1994. Students were exposed to a form of blended learning where they were given free access to a MOOC platform and were required to participate in seminars and sessions facilitated by an on-site teaching fellow (Bartholet et al., 2013). Now that they have proven the success of the pre-pilot course, Generation Rwanda is working towards expanding its scope to award associate's and even bachelor's degrees to empower young Rwandans and equip them with skills and knowledge necessary to move out of poverty.

While universities have been willing to provide education through traditional teaching methods, less attention has been 
paid to comparative educational effectiveness (McPherson \& Bacow, 2015). Nonetheless, a comprehensive understanding of educational effectiveness is necessary because pedagogy cannot merely be divided into two parts: online and offline. In addition, as McPherson and Bacow (2015) observed, the ways in which traditional instruction is delivered vary as greatly as students' learning outcomes, and thus, educational effectiveness should be accurately measured by "well-defined and valued outcomes" (146).

Returning to the subject matter, KOICA faces difficulties in managing and sustaining aid because its aid is dispersed across too many countries regardless of geographic proximity. For instance, it is difficult to visit and even more difficult to periodically visit these broadly situated scholarship recipient countries because of time and resource constraints. In contrast, Japan only considers few countries in Asia which makes organizing promotional fairs, alumni gatherings, interviews, and providing prerequisite courses for prospective students much easier (Oh, 2017). Management of education aid programs occur systematically.

Following this line of alternative thinking, establishing an online platform could be a pragmatic solution to address Korea's realistic challenges. Online interviews can be conducted as an alternative to face-to-face interviews, and lectures can be substituted by online courses. Sustaining long-term relationships with graduates would also become much easier. Another viable option is to reduce students' length of stay in Korea: The current KOICA scholarship program for a master's degree requires scholarship recipients to stay in Korea for sixteen months, and this could be reduced to six months or even less if students could fulfill education requirements by taking courses online. Furthermore, an online education platform could bring new opportunities for international cooperation. Because harmonization between aid donor countries will increase, countries could collaborate on creating contents for online education and facilitate dual or joint degree programs to attract more competent students.

In this regard, Nagoya University's Asian Satellite Campuses Institute (ASCI) is a representative case example of an online learning platform; there are six established satellite campuses in Asia, namely, Uzbekistan, Laos, Mongolia, Vietnam, Cambodia, and the Philippines. This is in sharp contrast to the conventional concept of satellite campus where a main campus has associated branches located primarily domestically. As Table 4 illustrates, ASCI offers doctoral degrees in six major fields of study: education and human development, bio-agricultural sciences, law, international development, medicine, and environmental studies. More interestingly, distance education and communication tools are effectively utilized to help students engage in the learning process. Enrolled students are only required to visit the main campus to attend short-term intensive academic seminars that are fully funded by the university.

Table 4. Degrees offered through the ASCI program

\begin{tabular}{llll}
\hline & Fields of the programs & Degree & Term/Country \\
\hline $\begin{array}{l}\text { Graduate School of } \\
\text { Education and Human }\end{array}$ & Educational Sciences, & Ph.D. in Education and & 3 years \\
Psychology and & Psychology & (M1, U) \\
Graduate School of Law & Legal institution design & $\begin{array}{l}\text { Doctor of Laws in } \\
\text { Comparative Law }\end{array}$ & 3 years \\
Graduate School of Medicine & Healthcare administration & Ph.D. in Medical Science & 4 years \\
Graduate School of & & & (V, C, M1, L, U, M2) \\
Bioagricultural Sciences & Food production and & Ph.D. in Agricultural & 3 years \\
Graduate School of & Economic and social & Ph.D. in International & 3 years \\
International Development & development & Development & (C, P) \\
Graduate School of & Environmental problem & Ph.D. in Environmental & 3 years \\
Environmental Studies & and environmental policy & Studies, Geography, & (M1, L) \\
\hline
\end{tabular}

Source: From http://asci.nagoya-u.ac.jp/about_asci/ (Nagoya University, n.d.).

Notes:

1. V: Vietnam, C: Cambodia, M1: Mongolia, L: Laos, U: Uzbekistan, P: Philippines, M2: Myanmar.

2. Graduate School of Medicine's program in Myanmar is offered without a satellite campus.

KOICA could adopt a similar satellite-campus model to effectively manage and sustain its inbound education ODA's 
long-term scholarship programs. Satellite campuses could be established on each continent and could expand if regional scholarship recipients increase in number. As aforementioned, most of the courses should be offered online; however, students could regularly come together to the regional satellite campuses to take courses that require physical human interactions. Faculty members will be composed mostly of local teaching staff, supplemented with instructors from the main campus; these instructors should supervise students taking online courses in their individual households and provide direct assistance through offline seminars. Students can visit the main campus only once or twice for intensive seminars, thesis defense, commencement, etc., all of which will overcome obstacles in distance education (Figure 1). This would also greatly reduce KOICA's substantial financial burden for the personal living expenses of scholarship recipients for 16 months. Moreover, with reduced costs, creating a doctoral degree program — which is in high demand among scholarship recipients - may become quite feasible. ASCI's model could be directly applied to KOICA and its inbound education scholarship program.

Once KOICA establishes this type of education platform through several universities (main campuses in Korea with their corresponding satellite campuses), collaborating with other agencies and universities will become much easier from sharing learning contents to establishing joint degree programs. This will eventually bring about harmonization in international development, one of the major components in the Paris Declaration of Aid Effectiveness along with country ownership and alignment.

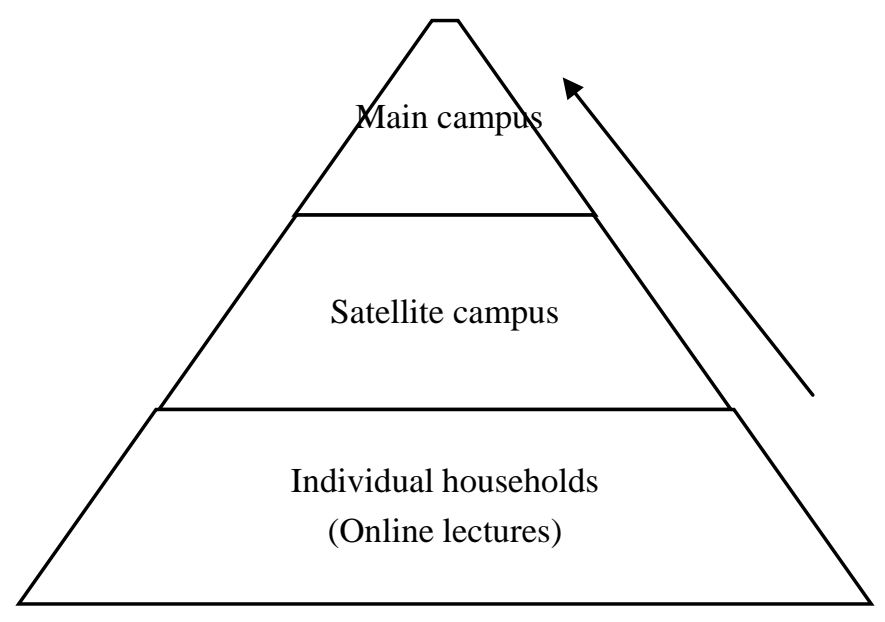

Figure 1. Three-step approach to online learning

\section{Conclusion}

This study examines the pattern of inbound education ODA of the United Kingdom, Germany, and Australia, the three major aid donor countries affiliated with the DAC. The empirical findings were significant in explaining the predictions of the gravity model; specifically, they showed higher concentrations of education ODA in all three aid donor countries. Population, GDP, and ODA dummy variable, otherwise known as proxies for mass, were expected to have a positive relationship with the number of scholarship recipients. Though all relationships were significant, population showed the highest, most consistent statistical significance. We expected to observe a clearly negative relationship between the time-invariant variable distance and the number of scholarship recipients, and this was also the case for the three aid donor countries.

To re-address the issues of aid management and sustainability, this study proposes establishing an online education platform as a viable solution. To elaborate, the satellite campus model readily verified by Nagoya University's ASCI can be considered to reduce the costs of accommodating inbound education scholarship recipients. Because Korea has dispersed its education ODA funds across countries in disparate locations regardless of geographic proximity, visiting all of the scholarship recipient countries is difficult; with an online education platform, much work can be transferred to the online platform and to the regional satellite campuses. Online lectures, interviews, and communication mechanisms can be facilitated to increase cost and time efficiency as well as effectiveness. In addition, online education platform gives the opportunity to foster collaborative relationships with other donor countries by means of activities such as online learning content development, course exchange, and joint degree programs. Korea could utilize an online education platform as a tool to overcome geographic barriers and increase connectivity by innovatively optimizing the resources that are readily available. 


\section{References}

Baldwin, R., \& Taglioni, D. (2006). Gravity for Dummies and Dummies for Gravity Equations. https://doi.org/10.3386/w12516

Bartholet, J., Norvig, P., Khan, S., Agarwal, P., Lue, R., Fletcher, S., Duncan, A. (2013). Special Report: Learning in the Digital Age. Scientific American, 309(2), 48-73. https://doi.org/10.1038/scientificamerican0813-72

Carey, K. (2016). The End of College: Creating the Future of Learning and the University Everywhere. New York: Riverhead Books.

Foreign and Commonwealth Office. (2018). Transparency data: United Kingdom Overseas Territory names. Retrieved from https://www.gov.uk/government/uploads/system/uploads/attachment_data/file/541077/territory-names.csv/preview

Harasim, L. (2000). Shift happens: Online Education as a New Paradigm in Learning. The Internet and Higher Education, 3(1-2), 41-61. http://dx.doi.org/10.1016/S1096-7516(00)00032-4

McCallum, J. (1995). National borders matter: Canada-U.S. regional trade patterns. American Economic Review, 85(3), 615-623. Retrieved from https://www.jstor.org/stable/2118191?seq=1\#page_scan_tab_contents

McPherson, M., \& Bacow, L. (2015). Online Higher Education: Beyond the Hype Cycle. Journal of Economic Perspectives, 29(4), 135-154. http://dx.doi.org/10.1257/jep.29.4.135

Nagoya University Asian Satellite Campuses Institute. (N.d.). About ASCI. Retrieved from http://asci.nagoya-u.ac.jp/about_asci/

OECD. (2012). Korea [PDF document]. Retrieved from http://www.oecd.org/dac/peer-reviews/Korea\%20CRC\%20-\%20FINAL\%2021\%20JAN.pdf

Oh, J. (2017). Spread or Concentrated: Where is South Korean Inbound Education Aid Aimed and Where Should it be directed? A Comparison with the Japanese Case. Review of Urban \& Regional Development Studies, 29(2), 114-134. https://doi.org/10.1111/rurd.12064

Ossiannilsson, E., Altinay, Z., \& Altinay, F. (2016). Transformation of Teaching and Learning in Higher Education towards Open Learning Arenas: A Question of Quality. In P. Blessinger \& T. Bliss (Eds.), Open Education: International Perspectives in Higher Education (pp. 159-177). Cambridge: Open Book Publishers. https://doi.org/10.11647/OBP.0103.08

U.S. Department of State. (2018). Independent States in the World. Retrieved from https://www.state.gov/s/inr/rls/4250.htm

United Nations. (N.d.). Member States. Retrieved from http://www.un.org/en/member-states/\#gotoS

Wei, S.-J. (1996). Intra-national vs. international trade: How stubborn are nations in global integration? National Bureau of Economic Research Working Paper 5531. https://doi.org/10.3386/w5531

\section{Copyrights}

Copyright for this article is retained by the author(s), with first publication rights granted to the journal.

This is an open-access article distributed under the terms and conditions of the Creative Commons Attribution license (http://creativecommons.org/licenses/by/4.0/). 